Doctorate Studies

\title{
Reasons why Dutch novice nurses leave nursing: A qualitative approach
}

\author{
J.H.A.M. Kox ${ }^{\text {a,b, }{ }^{*}, \text { J.H. Groenewoud }}{ }^{\text {a }}$, E.J.M. Bakker ${ }^{\text {a,d }}$, S.M.A. Bierma-Zeinstra ${ }^{\text {b, }}$, \\ J. Runhaar ${ }^{\mathrm{b}}$, H.S. Miedema ${ }^{\mathrm{a}}$, P.D.D.M. Roelofs ${ }^{\mathrm{a}, \mathrm{b}}$ \\ ${ }^{a}$ Rotterdam University of Applied Sciences, Innovations in Care, Rotterdam, the Netherlands \\ ${ }^{\mathrm{b}}$ Erasmus Medical Center, Department of General Practice, Rotterdam, the Netherlands \\ ${ }^{\mathrm{c}}$ Erasmus Medical Center, Department of Orthopaedics, Rotterdam, the Netherlands \\ ${ }^{\mathrm{d}}$ Amsterdam UMC, Vrije Universiteit Amsterdam, Department of Public and Occupational Health, Amsterdam Public Health Research Institute, Amsterdam, the \\ Netherlands
}

\section{A R T I C L E I N F O}

\section{Keywords:}

Professional turnover

Attrition

Dropout

Novice nurses

Thematic analysis

\begin{abstract}
A B S T R A C T
Shortages in the nursing profession are increasing. It is, therefore, imperative to understand why novice nurses are leaving the profession. This qualitative study explores Dutch novice nurses' motives for leaving the profession. Individual semi-structured interviews were held with seventeen former novice nurses who had decided to leave nursing within two years after graduation. Data was collected and analysed following the principles of Thematic Analysis, leading to six themes; 1) Lack of challenge; ambitious to progress further in management or research roles. 2) Lack of passion; no feeling of passion for patient care. 3) Lack of perceived competence; not feeling "up to the challenge". 4) Lack of job satisfaction due to heavy workload; work-life imbalance and inability to deliver high-quality care. 5) Lack of work capacity due to non-work-related health conditions; unmet requirements for job or work environment adjustment. 6) Lack of feeling of belonging; suffering from a negative attitude of colleagues to one another. To prevent novice nurse professional turnover, measures such as capacity building, supervisor support and a tailored personal development plan could be taken. To make novice nurses feel safe and reassured, support from colleagues and supervisors is important. Such measures require thoughtful implementation and evaluation.
\end{abstract}

\section{Introduction}

The demand for nurses is high worldwide (WHO, 2018), but the dropout rates are high as well (Currie and Hill, 2012). Novice nurses are especially vulnerable for dropout from the nursing profession (e.g., Beecroft et al., 2008; Parker et al., 2014). They undergo a period of stress and anxiety, role adjustment and shock when faced with the reality of beginning practice as a licensed nurse (Blomberg et al., 2016; Gardiner and Sheen, 2016; Hezaveh et al., 2014; Horsburgh and Ross, 2013; Powers et al., 2019), and do not feel skilled, comfortable or confident for up to one year after being employed as a nurse. The reality of independent nursing practice far exceeds the artificial experiences of nursing school and hospital-based trainings (Urban and Barnes, 2020). Some nurse administrators, nurse managers and physicians, on the other hand, expect the novice nurses to rapidly function as competent nurses (Norris, 2019; Theisen and Sandau, 2013; Urban and Barnes, 2020).

Considering the challenges accompanying the transition from student nurse to novice nurse, the reasons for turnover in novice nurses will be different compared to nurses with longer professional experience.

Definitions of nurse turnover vary. Brewer et al. (2012) define turnover as occurring when nurses leave a health care organization rather than their nursing job, profession or career. In this definition, a novice nurse can still continue working as a nurse in another nursing job (job turnover). Professional turnover is defined as occurring when nurses leave the nursing profession or career (Currie and Hill, 2012).

Novice nurse job turnover has been the subject of many qualitative and quantitative studies (e.g., Beecroft et al., 2008; Brewer et al., 2012; Chênevert et al., 2016; Flinkman and Salanterä, 2015; Suzuki et al., 2010). Only few studies (e.g., Chachula et al., 2015; Rudman et al., 2014) explicitly studied professional turnover.

Actual figures on novice nurse professional turnover are scarce. Studies in New Zealand, Canada and Europe show that the percentage of novice nurses leaving the nursing profession may be as high as $30 \%$

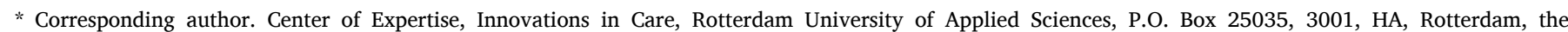
Netherlands.

E-mail address: j.h.a.m.kox@hr.nl (J.H.A.M. Kox).
} 
(Hasselhorn et al., 2005; New Zealand Nurses Organization, 2011: cited in Chachula et al., 2015). In the Netherlands, approximately one out of ten graduated nurses are not working in the field of nursing one year after graduation (Statistics Netherlands, 2019c). Insight in the reasons for novice nurses to leave the profession can provide direction for strategies that may contribute to their retention. In the Netherlands, guidelines to support novice nurses in their first job after graduation are lacking (Ten Hoeve et al., 2018). Novice nurses often start their career as a registered nurse without a transition programme. The length and content of transition programmes, if any, vary per health care institution. This is not different in the United States or the United Kingdom, where a broad range of transition programmes exists (Brook et al., 2019; Edwards et al., 2015). However, there is no conclusive evidence for the efficiency of such programmes (Brook et al., 2019; Edwards et al., 2015). Insight in the reasons for professional turnover in novice nurses may guide the development of a possible transition intervention. Our qualitative study on the reasons for professional turnover in novice nurses is performed in the context of a larger study on professional resilience in nursing students and new graduated nurses (SPRiNG) in the Netherlands (Bakker et al., 2018, 2019).

In the current study, we define novice nurse professional turnover as the turnover from bedside nursing or from the nursing profession altogether.

\section{Aim}

This study aimed to unravel Dutch former novice nurses' reasons, experiences and the circumstances that contributed to their professional turnover within two years after graduation, based on interviews with 17 participants who had left the nursing profession as bedside nurses.

\section{Research design}

We performed an exploratory qualitative study using semi-structured interviews to gather in-depth information on the reasons, experiences and circumstances that contribute to novice nurse turnover from bedside nursing or from the nursing profession altogether.

\section{Methods}

\subsection{Sample, participants, recruitment and selection}

The study population consisted of Dutch intermediate vocational and Bachelor degree nurses who had decided to leave the profession within two years after graduation. A volunteer (convenience) sample was used because there is no registry of professional turnover. For the recruitment of participants, we made use of the following recruitment methods. An advert was posted in the community forum of Stichting IZZ (a health insurance company for healthcare professionals), through deRotterdamseZorg (a health care employment network in Rotterdam), in Nursing (a Dutch sector magazine for the nursing profession) and in personal (JK) networks and social media (LinkedIn, Twitter, and Facebook). In total, 37 former nurses reacted to these adverts by sending an email to the research team. In response they received a standardised email invitation and, if necessary, a reminder within 2 weeks. Unfortunately, 18 respondents did not meet the criteria for inclusion, because they were still working as a nurse, they had not graduated as a nurse, or had been working as a graduated nurse for more than two years; or they decided not to participate. Two other respondents did not respond to the initial nor the reminder email invitation. Finally, we recruited seventeen respondents for our study, involving former registered nurses from both Bachelor and intermediate vocational level, from a good national spread all over urban and rural areas in The Netherlands. All included respondents considered themselves to have dropped out of the nursing profession. Table 1 shows the characteristics of the included respondents. Our sample was not as diverse regarding gender and ethnical background as we would have wished for if purposeful sampling had been possible; we could include only one male participant and none of the respondents had a non-Western background.

\subsection{Data collection}

Individual face-to-face semi-structured interviews were conducted between January and June 2018 by two healthcare researchers JK (male) and $\mathrm{PH}$ (female), trained in qualitative research. Both interviewers have a Master's degree and are registered nurses and lecturers in nursing. An interview guide with topics and open questions was used (Appendix 1). The interview guide was constructed using relevant literature (Casey et al., 2004; Chachula et al., 2015; Chênevert et al., 2016; Oermann and Garvin, 2002; Ten Hoeve et al., 2018) and by discussing the topics with all co-authors. The order in which the questions were presented depended on the replies of the respondents. Respondents were encouraged to give in-depth information regarding their reasons for leaving the nursing profession. The interviews lasted for about $1 \mathrm{~h}$ and were held at a place preferred by the respondent. All interviews were audio-recorded and transcribed verbatim. One interview took place in the presence of the respondent's mother; this had no impact on the quality of the collected data. At the start of each interview, demographic data were collected, such as age, gender, educational level, and time between graduation and exit (see Table 1).

\subsection{Ethical considerations}

All respondents received verbal and written information about the study, and were assured of complete confidentiality and the possibility of opting out during the study. All respondents gave written consent. No identifying information of respondents is presented and all quotes are anonymized.

The study meets the requirements of the Netherlands Code of Conduct for Scientific Practice from the Association of Universities in the Netherlands (2012). The study was exempted from formal medical ethical review in accordance with the Dutch Medical Research Involving Human Subjects Act (WMO) (CCMO, 2019).

\subsection{Data analysis}

For data analysis, the principles of Thematic Analysis were followed (Braun and Clarke, 2012). Two authors (JK and HG) independently analysed all interviews.

First, transcripts were read and reread to become familiar with the data. Second, an inductive analysis was performed by assigning codes to meaningful lines or fragments of data texts. For this analysis, relevant attributes were elaborated and cases were defined, grouped and constructed by means of these attributes. Next, common themes were identified, differences in themes were discussed and overlapping themes were combined or renamed. The research process moved from data collection to data analysis and back until the description was comprehensive, as an iterative process. This analysis process continued until no new information was identified; Hennink et al. (2017) suggest that meaning saturation may be obtained with 16-24 interviews. Each co-author (EB, SBZ, JR, PR, HM) analysed one or two interviews, eight in total, in order to reach consensus on the major themes. Key points from each interview were summarised on an A4 sheet and discussed by all authors.

The qualitative analysis package Atlas.ti 7.5.7 was used for analysis (Friese, 2014). The results of the study were reported using a 32-item checklist for interviews and focus groups: Consolidated Criteria for Reporting Qualitative research (COREQ) (Tong et al., 2007).

\subsection{Strategies to ensure rigour}

The first two authors (JK and HG) analysed the ad-verbatim 
Table 1

Characteristics of included respondents.

\begin{tabular}{|c|c|c|c|c|c|c|}
\hline Respondent & Gender & Age & $\begin{array}{l}\text { Nursing } \\
\text { education }^{\text {a }}\end{array}$ & Last clinical area & $\begin{array}{l}\text { Time between graduation } \\
\text { and exit (in months) }\end{array}$ & Current occupation; study ${ }^{c}$ \\
\hline 1 & Female & 27 & $\mathrm{BN}$ & General hospital (internal medicine unit) & 2 months & $\begin{array}{l}\text { Trainee teacher (in nursing); studying Master } \\
\text { of Nursing Science }\end{array}$ \\
\hline 2 & Female & 27 & $\mathrm{BN}$ & District nursing (home care) & 24 months & Trainee teacher (in nursing) \\
\hline 3 & Female & 24 & $\mathrm{BN}$ & District nursing (home care) & 15 months & Workplace trainer \\
\hline 4 & Female & 40 & $\mathrm{BN}$ & $\begin{array}{l}\text { Mental health care (addiction and psychosis } \\
\text { unit) }\end{array}$ & 12 months & Researcher; $\mathrm{PhD}$ candidate \\
\hline 5 & Female & 27 & $\mathrm{BN}$ & $\begin{array}{l}\text { Did not work as a RN (last internship: health } \\
\text { technology unit) }\end{array}$ & $\mathrm{N} / \mathrm{A}^{\mathrm{b}}$ & Teacher; teacher training (in nursing) \\
\hline 6 & Female & 25 & $\mathrm{BN}$ & Elderly care & 24 months & $\mathrm{N} / \mathrm{A}^{\mathrm{b}}$ (maternity leave) \\
\hline 7 & Male & 37 & $\mathrm{VN}$ & $\begin{array}{l}\text { General hospital (emergency unit - } \\
\text { observatory) }\end{array}$ & 24 months & Pharmaceutical account manager \\
\hline 8 & Female & 23 & $\mathrm{BN}$ & General hospital (flexpool) & 12 months & $\begin{array}{l}\text { Catering sector/travelling; studying Master of } \\
\text { Health Sciences }\end{array}$ \\
\hline 9 & Female & 22 & $\mathrm{BN}$ & $\begin{array}{l}\text { Did not work as a RN (last internship: } \\
\text { General hospital - cardiology unit) }\end{array}$ & $\mathrm{N} / \mathrm{A}^{\mathrm{b}}$ & $\begin{array}{l}\text { N/A }{ }^{b} \text { (in between studies); registered for } \\
\text { studying Master of Political Science }\end{array}$ \\
\hline 10 & Female & 29 & $\mathrm{VN}$ & Geriatric rehabilitation care & 24 months & Childcare/after-school care \\
\hline 11 & Female & 35 & $\mathrm{BN}$ & Nursing home & 12 months & $\begin{array}{l}\text { Intake coordinator for elderly care (no nursing } \\
\text { requirement) }\end{array}$ \\
\hline 12 & Female & 21 & $\mathrm{VN}$ & Secondment agency (rehabilitation center) & 10 months & $\begin{array}{l}\text { Surgical technician; surgical technology } \\
\text { training }\end{array}$ \\
\hline 13 & Female & 30 & $\mathrm{VN}$ & Center for disabled \& handicapped adults & 21 months & $\mathrm{N} / \mathrm{A}^{\mathrm{b}}$ (sick leave) \\
\hline 14 & Female & 25 & $\mathrm{BN}$ & $\begin{array}{l}\text { General hospital (gastrointestinal and } \\
\text { nephrology unit) }\end{array}$ & 8 months & $\mathrm{N} / \mathrm{A}^{\mathrm{b}}$ (in between jobs) \\
\hline 15 & Female & 23 & $\mathrm{BN}$ & General hospital (stroke unit) & 2 months & $\begin{array}{l}\text { Temporary agency worker (helpdesk for } \\
\text { Electronic Patient Records) }\end{array}$ \\
\hline 16 & Female & 24 & $\mathrm{BN}$ & $\begin{array}{l}\text { General hospital (gastrointestinal and liver } \\
\text { surgical unit) }\end{array}$ & 21 months & $\begin{array}{l}\mathrm{N} / \mathrm{A}^{\mathrm{b}} \text { (Wants work in a different job abroad, } \\
\text { not nursing) }\end{array}$ \\
\hline 17 & Female & 29 & $\mathrm{BN}$ & $\begin{array}{l}\text { General hospital (maternity and obstetrics } \\
\text { unit) }\end{array}$ & 9 months & $\begin{array}{l}\text { Junior safety instructor at an emergency } \\
\text { response office }\end{array}$ \\
\hline
\end{tabular}

${ }^{\text {a }} \mathrm{BN}=$ Bachelor degree trained nurse; $\mathrm{VN}=$ intermediate vocational degree trained nurse. In the Netherlands, the nursing profiles and nursing activities of Bachelor

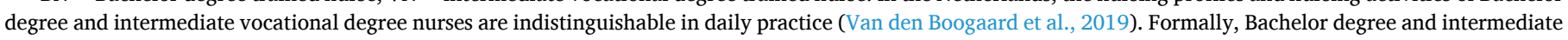
vocational degree nurses are both registered under the title 'nurse' in the official Dutch registry for nurses (the 'BIG-register').

b $\mathrm{N} / \mathrm{A}=$ Not Applicable.

c Some of the respondents chose for another role in health care instead of bedside nursing, meeting our definition of novice nurse professional turnover.

transcripts of all interviews. They discussed the assigned codes to come to an agreement. Investigator triangulation was applied to increase credibility (Farmer et al., 2006), by in-depth discussion with each co-author of the major themes of one interview and collaborate discussion of the key-points of all interviews. To ensure dependability, all research steps, including data gathering, data analysis and manuscript preparation were well-documented. Reflections on reflexivity, in particular potential preconceptions, were discussed between the first and second author.

\section{Results}

Six main themes emerged from the interviews as reasons for turnover (see Fig. 1). The six themes and their interrelationships will be explained in more detail.

\subsection{Lack of challenge}

Lack of challenge concerned the lack of diverse and more complex technical nursing tasks as well as the absence of professional opportunities, such as for clinical leadership or innovation. Various respondents had ambitions to improve the quality of care and sought to empower the nursing profession. However, the professional culture in various healthcare settings hampered novice nurses to take the lead in innovations. In this context, several respondents mentioned that it is important that motivated nurses are offered opportunities for their professional and personal development. Some respondents, decided to leave the profession because they were unable to do anything with their ambitions:

But that aspect of thinking at a higher level ... that just didn't happen there. [...]. I soon noticed that I couldn't get enough out of it for myself, that there was nothing more in it for me at that time. You know, that puzzle of ... gosh, he [the patient] needs this, but I can offer that, how are we going to do this? That's the real reason why I left the profession in that way. That I wasn't really getting out of it what I'm actually looking for. (2)

I still found the contact with the people very nice and interesting. But I wanted some more intellectual challenges. I wanted to do more ... I wanted to think and work more on a higher level and not so much the practical work, but higher level stuff. Policy management, that kind of thing. That's what I very much missed in my work as a nurse [...] Then you're doing things and then you have to ask the doctor again, like gosh, I've done this or that. [...]. I wanted to think about it myself. [ .... ] (4)

Some respondents mentioned the discrepancy they experienced between nursing as it was taught at school and how it was in practice. Two respondents had expected nursing to be more theoretical and analytical, but felt in practice that it mainly involved practical work, which did not satisfy their ambitions. These respondents were pessimistic about their career opportunities as a practical nurse and saw this as 'hitting a dead end':

In practice, you have to perform every role; you're a phone operator and you have to make the beds and you have to help patients go to the toilet, and yes. Just a lot of minor tasks. That was ultimately not my ambition. [...] At one point I thought, it feels a bit like a dead end, and then what? Being a nurse, OK, and that's it. Yes, I think that is in fact the difference between what you are trained for and what you really do in practice. (7)

Generally, the respondents who experienced a lack of challenge made a more rational decision to leave bedside nursing rather than an 


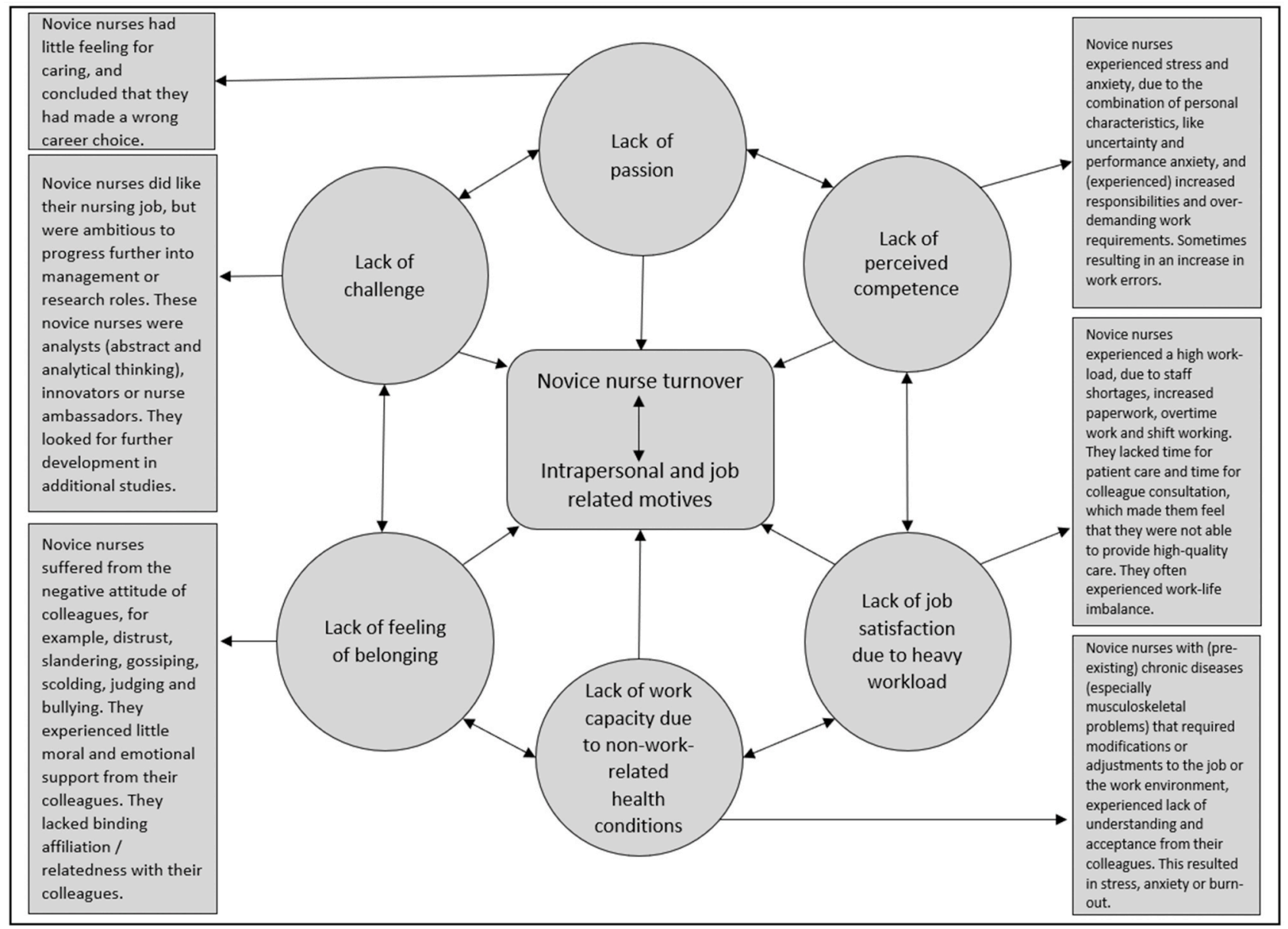

Fig. 1. Interaction of themes in novice nurse turnover.

emotional decision. They made a deliberate choice to switch to a career outside (bedside) nursing.

Most respondents did not mention the salary as the principal reason for leaving the nursing profession. For some respondents, however, especially the ones who lacked challenge in their nursing work, the salary was an issue:

And then there's also the fact that I thought gosh ..., it sounds bad, because I really don't need a top salary from a bank or whatever. But I found the salary very minimal. I thought, we have to promote ourselves much more as a profession and then the salaries can also increase. (4)

\subsection{Lack of passion}

Some respondents had wanted to become a nurse from childhood, but felt very soon during their nursing education that nursing was not their dreamed-off profession. Their expectations did not match the workplace reality. Typically, they liked the theoretical courses, such as anatomy and pathology. However, when doing their practical training, they discovered that they lacked the affinity with caring work, and this did not change after graduation. During the interviews it became clear that these respondents had already had doubts during their study about whether their ambition to become a nurse was the right one. They said they lacked the passion for working as a nurse:

Well what I noticed during the training, there were always girls who had [...] a real passion for the work, you know. And that is what I noticed in my colleagues as well. They have real passion, and that's what they say as well. And then I think yeah, I just don't feel that. I really don't feel it. (16)

But, yeah, I don't know, I still kept noticing, the further I got in my education, that I missed a certain passion. The work pressure was incredibly high. And I didn't really feel the passion to continue with what I was doing. [...] that was really a critical point for me. (15)

\subsection{Lack of perceived competence}

After graduating, some respondents felt that they were not yet "up to the challenge". They experienced a large transitional gap from student nurse to a more autonomous professional role. These respondents lacked confidence and missed the back-up from experienced nurses, which they had experienced during their practical training. After graduation, they felt that they were supposed to know everything. Due to staff shortages, however, the backup from more experienced nurses was often missing. Some respondents had mixed feelings about their perceived inability to cope with the increased responsibilities of patient care being the reason for leaving nursing so soon after graduation:

I continuously felt that I was not up to the challenge. Yes, of course, I was competent, but in community care, there weren't so many nursing procedures to be done. So for almost all procedures, I first needed to become competent myself. I didn't have that much experience. So if someone told me "Oh, that patient needs to be catheterised this afternoon, you can do that, can't you, because you're qualified". Well then I really thought, gosh, I'll have to look up the protocol first, and can someone please talk me through it. (11) 
I also struggled with the responsibility there [internal medicine ward]. Indeed, the idea that when patients deteriorate, like oh, what have I done. Have I got a good overview? Did I forget anything? And I think that there wasn't enough attention [from colleagues] for me to express my doubts, or for discussing things or working together. OK, perhaps I shouldn't see things so negatively, that everything is purely my responsibility, but that I also have colleagues who can support me. That I don't have to do things all by myself. (14)

\subsection{Lack of job satisfaction due to heavy workload}

In several cases, job satisfaction was hampered by a heavy workload due to staff shortages, rotating night shifts, working overtime, increased paperwork and patient violence.

With regard to staff shortages, some respondents mentioned that they, as novice nurses, had sole responsibility for the ward, or had responsibility together with inexperienced staff such as temporary workers. It was also reported that new colleagues are used, or even misused, to fill in the unpopular gaps in the work schedule. One respondent said that novice nurses should be aware of that and set limits for themselves for their own protection, to make them less vulnerable early in their career:

When there is a new colleague, the first response is "great, we have staff". We'll use her to fill the holes everywhere. And before you know it you're just scheduled, and then you just have to deal with it. Of course that shouldn't be the case, because you also have a voice yourself, and you can also say what your limits are. And it sounds really bad, but you should be strict with your employer. And please pay attention to yourself [...]. I've learned all the rules, but that feeling you get when someone oversteps your personal boundaries, that needs training.(13)

In some instances, shift work made the work more burdensome. In particular, rotating night shifts had a negative effect on their family life and social life. Some respondents stated that they would never work shifts again because of the negative effect on their private life.

Other respondents mentioned that they frequently had to work overtime. They were called too often to work on their days off to cover for a sick colleague. It was hard for them to resist these calls, because they often felt responsible for both patients and colleagues. Respondents had to be assertive to refuse to go to work on their days off, but even if they did so, they sometimes felt guilty about letting down their patients or their team. For example, one of the respondents mentioned that she had to work for $12 \mathrm{~h}$ because the colleague that was scheduled for the next shift called in sick:

And that overwork, working overtime every day [...]. Officially after a late shift, my shift ended at 11:30 p.m., but most of the time I finally started the information handover to my colleague at 12:30 a. m., because of numerous patient calls. In such a situation I don't leave my night-shift colleague alone. It's not fair on the patients, not nice for my colleague, or for me, for anyone. So then we would do a patient round together, do the information transfer and finally, one hour or one and a half hours later, I could leave. Regularly. (10)

The unforeseen impact of patient violence, or violence by the patients' relatives, also contributed to the workload. Some respondents reported how the continuous threat of violence contributed to a feeling of unsafety and therefore to the psychosocial workload:

Well, I expected it [nursing] to be a tough job, yes, I did have that in mind. [...] Only that workload issue, the mental workload and aggression, I didn't see that coming. [...] Actually, we had to look over our shoulder regularly [...] and where the management fails to take measures, well, then you really feel like fair game. (17)
Respondents felt that the heavy workload hampered direct patient care. They were frustrated at not being able to provide the quality of care they wished to deliver. They would have liked to spend more time with their patients:

Not being able to offer the care that you would like to offer. And that was actually when I thought: No, this is just getting worse. The [staff] shortages will only increase and I don't want to continue like this. [...]. And there's always something up everywhere, that's true, [...] but in the end it's at the expense of patient care and that, yeah, that was really gnawing at me. (12)

Some respondents described how the heavy workload led to (near) incidents. Others were sometimes not sure whether they had done a specific task, or had done it correctly. One respondent spoke about her experience with the death of a patient, which kept her wondering for two days whether he patient's death was caused by her actions:

Yes. And that really gnaws at you, that when you're at home you start thinking, yes, hm, hm. Even when incidents happen that you're not directly involved in, you still think about them. I [as a district nurse] had a client who died very suddenly. I'd given insulin in the morning, and in the afternoon she was admitted with a hypo. And she died in the hospital that night; I thought, did I give her the right thing? Did I perhaps work in too much of a hurry? Well, in retrospect it turned out to be something else, but I felt very guilty about it for two days. Because you're just ... you, you need to double check everything [...], but in the end you get round the rules, because how can I double check things when I'm working on my own and the patient is blind as anything. (6)

Most novice nurses who had experienced a lack of work pleasure also reported having developed stress symptoms such as fatigue, sleeping problems, nightmares, tense muscles, headaches, worrying about the work, or lack of confidence at work:

You need to pay close attention to yourself, because if you were to drive yourself into the ground that would be quite a pity, of course. The only thing that bothered me was just tense muscles and my shoulders, but yeah, that was partly due to lifting, but also because of the work pressure on the ward, actually, due to stress. (8)

Quite frankly, I don't exactly know what happened with it [a nursing home that had fallen into disrepute] afterwards. But it meant [...] that during those six months, for example, I often dreamt that I was locked up in that ward. (9)

\subsection{Lack of work capacity due to non-work-related health conditions}

Some respondents were less employable due to pre-existing nonwork-related diseases. They did not always have the ability to work at full capacity. For instance, neuromusculoskeletal diseases hampered heavy lifting. Some respondents might have benefitted from flexible working conditions, e.g., starting later in the morning.

Often, they were confronted with a hostile attitude to their limited employability from their colleagues. This lack of understanding, acceptance and support from their colleagues added to the burden of work. As such, this theme was related to the theme lack of feeling of belonging'. One respondent found it hard to see her colleagues taking care of patients, but not taking care of each other:

Create a bit of acceptance in the workplace, I would say. Well, so that nurses and nursing assistants accept each other's disabilities, so to say. Instead of having to go on and on caring for other people. But actually, you have to take care of yourself first before you can take care of others. And that hardly happens at all in health care nowadays. (5) 
[...] Well, if I could have said; "Girls, I don't feel well in my joints today, I'm luxating and I'm in pain. Would it be possible to do the drugs round or would it be possible to just support the less complex patients with their ADL [Activities of Daily Living] instead of bedbathing a patient?" [...] But well, because the culture wasn't like that, I didn't do that, which was what I found most difficult. (1)

\subsection{Lack of feeling of belonging}

Some respondents did not feel really understood or supported by their colleagues. Sometimes, older colleagues had difficulty accepting the novice nurse's attitude and (novel) ideas. Such colleagues were reluctant to bring about changes in the way they used to provide care, and to make changes in their work routines. One respondent indicated that it was not easy to start working as a novice nurse because she, as a bachelor-trained nurse, was more qualified than most of her colleagues, who had received intermediate vocational training or less and who did not accept her innovative ideas. She was judged to be too young and inexperienced:

There were quite a few $50+$ nursing assistant colleagues who thought it [a novice nurse doing management tasks] wasn't appropriate. I was 24 when I started working there [in home care]. "No, you're far too young, what do you know?" and "You've just got a Bachelor degree, so all you've got is book learning". That kind of things. Obtaining their acceptance was very difficult. (6)

Sometimes there was a negative atmosphere at work due to the negative interpersonal relationships among colleagues, including distrust, slandering, gossiping, scolding and bullying. Some respondents felt unwelcome and undervalued. Although this negativity was not always directed towards the respondent, sometimes it was directed towards a colleague, but it still affected the respondent. Some respondents related this negative atmosphere to the predominantly female presence in the workplace. Unfortunate conditions, such as a sick colleague or organisational changes, could make the work atmosphere even less pleasant:

When the three of us [bachelor nurses] would sit down for an hour, for example [to discuss work strategies]. Then the team would say, "They are gossiping about everyone." Well, that kind of ideas. [...] We have had three communication training sessions, that also didn't have the intended result. Things just got worse. Everyone was getting suspicious. And there was no longer a safe climate. Hardly anyone came to the district nurses' office. (3)

How they [colleagues] behaved towards one another, it was a real revelation to me. Because it was, well, it was a women's world in fact. And that's what you feel, it's so nasty, it's so sly, so underhand, so ... (1)

\section{Discussion}

As far as we know, this is one of the few qualitative studies on the personal experiences of former novice nurses who left the profession within two years after graduation (professional turnover). Seventeen former novice nurses from The Netherlands were interviewed about their reasons for leaving bedside nursing. Six core themes emerged from the interviews.

One of the core themes found in our study was the lack of challenge. Some nurses decided to leave the nursing profession to fulfil their need for further professional and personal growth. The lack of intellectual challenge, restricted professional autonomy and limited professional opportunities in relation to dropout intention has also been reported by others (Flinkman et al., 2013; Fochsen et al., 2005). The intention to leave is also influenced by dissatisfaction with the remuneration
(Flinkman et al., 2013; Sjögren et al., 2005). Salary issues were also mentioned in our study as a contributing factor, but not as the main reason.

Lack of passion was another theme. For some respondents, their expectations of being a nurse did not match the workplace reality. Already during their practical training, they realised that they had made a wrong career choice, and this realisation was reinforced when they started working as a graduate nurse. A dissonance between expectations and experiences in novice nurses has been reported previously, resulting in a desire to leave the profession (Scott et al., 2008). Such dissonance is also reported in nursing students and was described as 'increasingly experiencing a mismatch between expectations and reality' (Bakker et al., 2019).

A third theme was lack of perceived competence. The transition from student to graduate nurse is challenging and may lead to stress, lack of confidence, feeling insecure and performance anxiety (Ortiz, 2016; Washington, 2012). Some respondents in our study were not able to cope with this transition because they did not feel "up to the challenge" and experienced increased responsibilities and excessively demanding work requirements. They were regularly troubled by a fear of making work errors. In addition, they received little or no back-up support from experienced colleagues due to staff shortages. This phenomenon already occurs in nursing students during internships. Bakker et al. (2019) described this as 'ending up in a downward spiral', where students lose their grip on the learning process and lack the support from the programme organization.

Lack of job satisfaction related to the heavy workload and excessive work requirements was another important reason for professional turnover in our study. The high workload of nurses is a topical and worldwide problem because of an ageing population (Snavely, 2016), the increased number of people with comorbidity, and the decreasing number of nursing staff available. Almost all respondents mentioned staff shortages, resulting in a lack of time for patient care and lack of time for consultation with colleagues. Increased paperwork was another reason mentioned by our respondents. Shift work, working overtime on a regular basis and unfavourable nurse-patient ratios were also recognised as factors in nurse turnover by Flinkman et al. (2013) and Shields and Ward (2001). Several respondents in our study experienced an imbalance between their work and their personal life. This was also acknowledged in the studies of Boamah and Laschinger (2016), Leong and Crossman (2015), Ten Hoeve et al. (2018), and Yamaguchi et al. (2016). Ten Hoeve et al. (2018) related this work-life imbalance to lower mental and physical well-being.

Lack of work-capacity due to non-work-related health conditions, such as chronic physical and mental health problems, was another theme. These health problems existed before starting working as a nurse. A qualitative study among registered nurses with various disabilities (mainly neurological and musculoskeletal disorders), some of whom were no longer working in nursing, reported that in order to retain nurses with disabilities, they should be supported by employers and colleagues (Neal-Boylan and Guillett, 2008). This support should include possibilities and suggestions for work that these nurses could do without experiencing problems. Another qualitative study (Neal-Boylan and Miller, 2017) revealed that nursing students with disabilities experienced difficulties in getting assistance or support in class and in clinical practice. In their study many participants felt compelled to hide their disability, and were more likely to disclose it to a trusted fellow student than to faculty.

The theme 'lack of a feeling of belonging' can be associated with relatedness. In their qualitative study of diary-described experiences of novice nurses during their first two years after graduation, Ten Hoeve et al. (2018) found that 'relatedness', meaning the need to experience a sense of belonging and attachment to other people, was one of the most reported themes. Both positive and negative experiences with regard to relatedness were reported. Positive perceptions made the nurses feel respected and contributed to job satisfaction, while negative experiences 
contributed to the intention to leave. A supporting working environment is essential for novice nurses and facilitates sharing their experiences and asking for help in stressful situations. This may help novice nurses to stay committed to the nursing profession (Ten Hoeve et al., 2018). In our study, support from colleagues and supervisors was considered important as well. Several respondents, however, had negative relatedness experiences, such as distrust, slandering, gossiping, scolding and bullying. Novice nurse scolding was also described by Leong and Crossman (2015) and was the major reason for leaving the nursing profession for some respondents. Whereas the negative relatedness in the study of Ten Hoeve et al. (2018) mainly involved the relationship between novice nurses and physicians, in our study it mainly involved the direct nursing colleagues. Some respondents felt unwelcome and undervalued. This was also seen in the study by Chachula et al. (2015). Positive collegial support in the first 12 months after graduation is considered to be essential for novice nurses to become more familiar with the job, and contributes to more self-confidence and job satisfaction (Ten Hoeve et al., 2018).

A strength of this study is that we gained in-depth, detailed information about the various professional turnover reasons from seventeen former novice nurses from various areas throughout The Netherlands; covering eight of twelve Dutch provinces and various clinical areas. The included respondents all considered themselves as dropouts from the nursing profession. Almost all of them, however, still felt a certain degree of affinity with the nursing profession and nursing work. Eight of them still have a job which is associated with the nursing profession. They are no longer proving direct bedside care, but work in a profession relating to nursing education or research. The vast majority of respondents ruled out to start working as a bedside nurse again in future, but some did not.

\subsection{Limitations}

Although Hennink et al. (2017) suggest that meaning saturation can be obtained with 16-24 interviews, certain topics in our study may not have reached meaningful saturation; some codes had stabilised and reached saturation, while aspects of other codes were still emerging. We may have missed themes related to dropout in novice nurses that would have appeared if we had a more diverse sample.

Also a limitation of the study was the volunteer sample of respondents. Because it was difficult to reach members of the target group, most of the respondents were recruited through an advert in a Dutch sector magazine for the nursing profession. Considering the relatively large number of novice nurses who dropout, we were only able to recruit 17 eligible respondents. Our study sample consisted of former registered nurses; the majority $(n=13)$ from Bachelor degree and four from intermediate vocational degree. In the Netherlands, the nursing profiles and nursing activities of these groups are indistinguishable in daily practice (Van den Boogaard et al., 2019). None of the participants in our study had a non-Western cultural background. This is quite remarkable as the proportion of inhabitants with a migrant background in the Netherlands in 2018 was $23.1 \%$ (Statistics Netherlands, 2019a), so, one would expect some respondents with a migrant background. This is a result of the sampling method. Also, the proportion of male respondents was small $(n=1)$. Among all health care workers in the Netherlands, the ratio of male nurses to female nurses is $2.3 \%-14.4 \%$ (Statistics Netherlands, 2019b). We cannot be sure whether other reasons for leaving the profession might have been put forward if there had been more respondents from these subgroups.

\section{Conclusions and recommendations}

We aimed to explore the experiences and circumstances of former novice nurses that contributed to their professional turnover. Six themes could be distinguished as reasons for leaving the nursing profession within two years after graduation. Four of these themes are related to intrapersonal motives for leaving, that is, lack of challenge, lack of passion, lack of perceived competence, and lack of work capacity due to non-work-related health conditions. Two themes concern job-related motives, that is, lack of job satisfaction due to a heavy workload, and lack of feeling of belonging.

To prevent novice nurse professional turnover, various measures can be taken. Based on our findings, we recommend capacity building for student and novice nurses, including provision of mentors and enhancement of the individual's self-esteem. Novice nurses with further professional, personal and intellectual ambitions should be given the opportunity to develop further in order to keep them motivated. Supervisor support and the development of a tailored personal development plan are essential for this.

Bedside nursing is a high workload profession. The effect of excessive workload is adverse on patient care and results in dissatisfaction, burnout and turnover among novice nurses. Healthcare organisations and governments should seek to manage the nursing workload effectively in order to reduce dissatisfaction and burnout.

To prevent attrition, it is essential that novice nurses receive effective support from their teams, colleagues and supervisors, so that they feel supported and reassured. In this context, it is also necessary for colleagues and supervisors to observe physical or psychological symptoms in novice nurses, and to provide an adequate response. A more welcoming workplace culture, as well as a supportive and coaching attitude of colleagues and supervisors, can help novice nurses to feel more affiliation, and feel more related.

It is important that the above-mentioned measures are not limited to novice nurses only. Nursing students can benefit from these measures as well, especially during the practical traineeships of their nursing education.

Future research is needed to develop and evaluate intervention programmes that contribute to a supportive environment with tailored coaching opportunities for both nursing students and novice nurses working in the different clinical areas.

\section{Declaration of competing interest}

The authors declare that they have no conflicting interests.

\section{Acknowledgements}

The authors acknowledge the support of Stichting IZZ and Nursing magazine for their support with the recruitment of participants. In this regard special thanks are due to Isa Bais and Rhijja Jansen. Special thanks are also due to Pia Helder for her participation in the interviewing process. Furthermore, we are grateful to all the former novice nurses who participated in the interviews. Through their valuable input we could provide more insight into the reasons for novice nurses' decisions to leave the nursing profession.

\section{Appendix A. Supplementary data}

Supplementary data to this article can be found online at https://doi. org/10.1016/j.nepr.2020.102848.

\section{Funding}

The authors thank the Netherlands Organisation for Scientific Research (NWO) and Rotterdam University of Applied Sciences for funding this research.

\section{Disclaimer}

The funding sources had no involvement in study design; in the collection, analysis and interpretation of data; in the writing of the report; and in the decision to submit the article for publication. 


\section{Ethics approval and consent to participate}

All respondents received verbal and written information about the study, and were assured of complete confidentiality and the possibility of opting out during the study. All respondents gave written consent. No identifying information of respondents is presented and all quotes are anonymized.

The study meets the requirements of the Netherlands Code of Conduct for Scientific Practice from the Association of Universities in the Netherlands (2012). The study was exempted from formal medical ethical review in accordance with the Dutch Medical Research Involving Human Subjects Act (WMO) (CCMO, 2019).

\section{References}

Association of Universities in the Netherlands, 2012. Netherlands Code of Conduct for Scientific Practice. VSNU, The Hague from. https://www.vsnu.nl/files/documente $\mathrm{n} /$ Domeinen/Onderzoek/The_Netherlands_Code_of_Conduct_for_Scientific_Practice 2012.pdf. (Accessed 10 October 2019).

Bakker, E.J., Kox, J.H., Miedema, H.S., Bierma-Zeinstra, S., Runhaar, J., Boot, C.R., van der Beek, A.J., Roelofs, P.D., 2018. Physical and mental determinants of dropout and retention among nursing students: protocol of the SPRiNG cohort study. BMC Nurs. 17 (1), 27. https://doi.org/10.1111/j.1564-913X.2006.tb00009.x.

Bakker, E.J., Verhaegh, K.J., Kox, J.H., van der Beek, A.J., Boot, C.R., Roelofs, P.D., Francke, A.L., 2019. Late dropout from nursing education: an interview study of nursing students' experiences and reasons. Nurse Educ. Pract. 39, 17-25. https:// doi.org/10.1016/j.nepr.2019.07.005.

Beecroft, P.C., Dorey, F., Wenten, M., 2008. Turnover intention in new graduate nurses: a multivariate analysis. J. Adv. Nurs. 62 (1), 41-52. https://doi.org/10.1111/j.13652648.2007.04570.x.

Blomberg, K., Isaksson, A.K., Allvin, R., Bisholt, B., Ewertsson, M., Kullén Engström, A., Ohlsson, U., Sundler Johansson, A., Gustafsson, M., 2016. Work stress among newly graduated nurses in relation to workplace and clinical group supervision. J. Nurs. Manag. 24 (1), 80-87. https://doi.org/10.1111/jonm.12274.

Boamah, S.A., Laschinger, H., 2016. The influence of areas of worklife fit and work-life interference on burnout and turnover intentions among new graduate nurses. J. Nurs. Manag. 24 (2), E164-E174. https://doi.org/10.1111/jonm.12318.

Braun, V., Clarke, V., 2012. Thematic analysis. In: Cooper, H., Camic, P., Long, D., Panter, A., Rindskopf, D., Sher, K. (Eds.), APA Handbook of Research Methods in Psychology, Research Designs: Quantitative, Qualitative, Neuropsychological, and Biological, vol. 2. American Psychological Association, Washington, DC, US, pp. 57-71.

Brewer, C.S., Kovner, C.T., Greene, W., Tukov-Shuser, M., Djukic, M., 2012. Predictors of actual turnover in a national sample of newly licensed registered nurses employed in hospitals. J. Adv. Nurs. 68 (3), 521-538. https://doi.org/10.1111/j.13652648.2011.05753.x.

Brook, J., Aitken, L., Webb, R., MacLaren, J., Salmon, D., 2019. Characteristics of successful interventions to reduce turnover and increase retention of early career nurses: a systematic review. Int. J. Nurs. Stud. 91, 47-59. https://doi.org/10.1016/j. ijnurstu.2018.11.003.

Casey, K., Fink, R.R., Krugman, A.M., Propst, F.J., 2004. The graduate nurse experience. J. Nurs. Adm. 34 (6), 303-311.

CCMO, 2019. Central committee on research involving human subjects. Your research: is it subject to the WMO or not? from. https://english.ccmo.nl/. (Accessed 10 October 2019).

Chachula, K.M., Myrick, F., Yonge, O., 2015. Letting go: how newly graduated registered nurses in Western Canada decide to exit the nursing profession. Nurse Educ. Today 35 (7), 912-918. https://doi.org/10.1016/j.nedt.2015.02.024.

Chênevert, D., Jourdain, G., Vandenberghe, C., 2016. The role of high-involvement work practices and professional self-image in nursing recruits' turnover: a three-year prospective study. Int. J. Nurs. Stud. 53, 73-84. https://doi.org/10.1016/j. ijnurstu.2015.09.005.

Currie, E.J., Hill, R.A.C., 2012. What are the reasons for high turnover in nursing? A discussion of presumed causal factors and remedies. Int. J. Nurs. Stud. 49 (9), 1180-1189. https://doi.org/10.1016/j.ijnurstu.2012.01.001.

Edwards, D., Hawker, C., Carrier, J., Rees, C., 2015. A systematic review of the effectiveness of strategies and interventions to improve the transition from student to newly qualified nurse. Int. J. Nurs. Stud. 52 (7), 1254-1268. https://doi.org/ 10.1016/j.ijnurstu.2015.03.007.

Farmer, T., Robinson, K., Elliott, S.J., Eyles, J., 2006. Developing and implementing a triangulation protocol for qualitative health research. Qual. Health Res. 16 (3), 377-394. https://doi.org/10.1177/1049732305285708.

Flinkman, M., Isopahkala-Bouret, U., Salanterä, S., 2013. Young registered nurses' intention to leave the profession and professional turnover in early career: a qualitative case study. ISRN. Nurs. 1-12. https://doi.org/10.1155/2013/916061, 2013.

Flinkman, M., Salanterä, S., 2015. Early career experiences and perceptions-a qualitative exploration of the turnover of young registered nurses and intention to leave the nursing profession in Finland. J. Nurs. Manag. 23 (8), 1050-1057. https://doi.org/ 10.1111/jonm.12251.

Fochsen, G., Sjögren, K., Josephson, M., Lagerström, M., 2005. Factors contributing to the decision to leave nursing care: a study among Swedish nursing personnel.
J. Nurs. Manag. 13 (4), 338-344. https://doi.org/10.1111/j.13652934.2005.00546.x

Friese, S., 2014. Qualitative Data Analysis with Atlas.Ti. Sage Publications., London, UK. Gardiner, I., Sheen, J., 2016. Graduate nurse experiences of support: a review. Nurse Educ. Today 40, 7-12. https://doi.org/10.1016/j.nedt.2016.01.016.

Hasselhorn, H.-M., Müller, B.H., Tackenberg, P., 2005. NEXT Scientific Report July 2005. University of Wuppertal, Wuppertal.

Hennink, M.M., Kaiser, B.N., Marconi, V.C., 2017. Code saturation versus meaning saturation: how many interviews are enough? Qual. Health Res. 27 (4), 591-608. https://doi.org/10.1177/1049732316665344.

Hezaveh, M.S., Rafii, F., Seyedfatemi, N., 2014. The experience of stress among new clinical nurses. Nurs. Prac. Today. 1 (4), 199-206.

Horsburgh, D., Ross, J., 2013. Care and compassion: the experiences of newly qualified staff nurses. J. Clin. Nurs. 22 (7-8), 1124-1132. https://doi.org/10.1177/ 1049732316665344.

Leong, Y.M.J., Crossman, J., 2015. New nurse transition: success through aligning multiple identities. J. Health Organisat. Manag. 29 (7), 1098-1114. https://doi.org/ 10.1108/JHOM-02-2014-0038.

Neal-Boylan, L., Miller, M., 2017. Treat me like everyone else: the experience of nurses who had disabilities while in school. Nurse Educat. 42 (4), 176-180. https://doi.org/ 10.1097/NNE.0000000000000348.

Neal-Boylan, L., Guillett, S.E., 2008. Work experiences of RNs with physical disabilities. Rehabil. Nurs. 33 (2), 67-72. https://doi.org/10.1002/j.2048-7940.2008.tb00206.x.

New Zealand Nurses Organisation, 2011. Why younger nurses quit nursing. N. Z. Nurs. J. 17 (10), 9.

Norris, T.L., 2019. Making the transition from student to professional nurse. In: Cherry, B., Jacob, S.R. (Eds.), Contemporary Nursing. ELSEVIER, St. Louis, Missouri, pp. 409-430.

Oermann, H., Garvin, F., 2002. Stresses and challenges for new graduates in hospitals. Nurse Educ. Today 22 (3), 225-230. https://doi.org/10.1054/nedt.2001.0695.

Ortiz, J., 2016. New graduate nurses' experiences about lack of professional confidence. Nurse Educ. Pract. 19, 19-24. https://doi.org/10.1016/j.nepr.2016.04.001.

Parker, V., Giles, M., Lantry, G., McMillan, M., 2014. New graduate nurses' experiences in their first year of practice. Nurse Educ. Today 34 (1), 150-156. https://doi.org/ 10.1016/j.nedt.2012.07.003.

Powers, K., Herron, E.K., Pagel, J., 2019. Nurse preceptor role in new graduate nurses' transition to practice. Dimens. Crit. Care Nurs. 38 (3), 131-136. https://doi.org/ 10.1097/DCC.0000000000000354.

Rudman, A., Gustavsson, P., Hultell, D., 2014. A prospective study of nurses' intentions to leave the profession during their first five years of practice in Sweden. Int. J. Nurs. Stud. 51 (4), 612-624. https://doi.org/10.1016/j.ijnurstu.2013.09.012.

Scott, E.S., Engelke, M.K., Swanson, M., 2008. New graduate nurse transitioning: necessary or nice? Appl. Nurs. Res. 21 (2), 75-83. https://doi.org/10.1016/j apnr.2006.12.002.

Shields, M.A., Ward, M., 2001. Improving nurse retention in the National Health Service in England: the impact of job satisfaction on intentions to quit. J. Health Econ. 20 (5), 677-701. https://doi.org/10.1016/S0167-6296(01)00092-3.

Sjögren, K., Fochsen, G., Josephson, M., Lagerström, M., 2005. Reasons for leaving nursing care and improvements needed for considering a return: a study among Swedish nursing personnel. Int. J. Nurs. Stud. 42 (7), 751-758. https://doi.org/ 10.1016/j.ijnurstu.2004.11.001.

Snavely, T.M., 2016. A brief economic analysis of the looming nursing shortage in the United States. Nurs. Econ. 34 (2), 98-101. Gale Document Number: GALE| A452050018.

Statistics Netherlands, 2019a. Population; key figures. from. https://opendata.cbs.nl/stat line/\#/CBS/en/dataset/37296eng/table?ts=1535630146207. (Accessed 7 February 2019).

Statistics Netherlands, 2019b. Zorg; werkgelegenheid, beroepen in zorg en welzijn, zorgaanbieders [Care; employment, occupations in care and welfare, care providers] from. https://opendata.cbs.nl/statline/\#/CBS/nl/dataset/83738NED/table?ts=15 35632310963. (Accessed 7 February 2019).

Statistics Netherlands, 2019c. AZW: HBO Verpleegkunde CROHO 34560; 2016/'172017/'18 from. https://www.cbs.nl/nl-nl/maatwerk/2019/14/azw-hbo-verplee gkunde-croho-34560-2016-17-2017-18. (Accessed 22 April 2020).

Suzuki, E., Tagaya, A., Ota, K., Nagasawa, Y., Matsuura, R., Sato, C., 2010. Factors affecting turnover of Japanese novice nurses in university hospitals in early and later periods of employment. J. Nurs. Manag. 18 (2), 194-204. https://doi.org/10.1111/ j.1365-2834.2010.01054.x.

Ten Hoeve, Y., Kunnen, S., Brouwer, J., Roodbol, P.F., 2018. The voice of nurses: novice nurses' first experiences in a clinical setting. A longitudinal diary study. J. Clin. Nurs. 27 (7-8), e1612-e1626. https://doi.org/10.1111/jocn.14307.

Tong, A., Sainsbury, P., Craig, J., 2007. Consolidated criteria for reporting qualitative research (COREQ): a 32-item checklist for interviews and focus groups. Int. J. Qual. Health Care 19 (6), 349-357. https://doi.org/10.1093/intqhe/mzm042.

Theisen, J.L., Sandau, K.E., 2013. Competency of new graduate nurses: a review of their weaknesses and strategies for success. J. Cont. Educ. Nurs. 44 (9), 406-414. https:// doi.org/10.3928/00220124-20130617-38.

Urban, R.W., Barnes, D.M., 2020. Transition to practice: the lived experience of new graduate nurses in early solo flight. J Nurses in Professional Develop 36 (2), 74-81. https://doi.org/10.1097/NND.0000000000000608.

Van den Boogaard, T.C., Roodbol, P.F., Poslawsky, I.E., Ten Hoeve, Y., 2019. The orientation and attitudes of intermediate vocational trained nursing students (MBOV) towards their future profession: a pre-post survey. Nurse Educ. Pract. 37, 124-131. https://doi.org/10.1016/j.nepr.2019.04.007. 
WHO, 2018. Nursing and Midwifery, Key Facts World Health Organization from. https ://www.who.int/news-room/fact-sheets/detail/nursing-and-midwifery. (Accessed 9 October 2019).

Washington, G.T., 2012. Performance anxiety in new graduate nurses: is it for real? Dimens. Crit. Care Nurs. 31 (5), 295-300. https://doi.org/10.1097/ DCC.0b013e3182619b4c.
Yamaguchi, Y., Inoue, T., Harada, H., Oike, M., 2016. Job control, work-family balance and nurses' intention to leave their profession and organization: a comparative crosssectional survey. Int. J. Nurs. Stud. 64, 52-62. https://doi.org/10.1016/j. ijnurstu.2016.09.003. 